\title{
A Study on How Disaster Issues Reported On the Ethiopian Print Media
}

\author{
Mulatu Alemayehu Moges \\ Addis Ababa University, Ethiopia
}

\begin{abstract}
As one of the eastern African Countries which are vulnerable for wide range of calamities, Ethiopia is continuingly affected by drought, famine and other disasters. In this context, the role of media is vital in supporting the action to be taken in disaster reduction. The media play in changing the life style and creating the awareness of the pastoral and agro pastoral communities for the betterment of their livelihoods. The overarching objective of this research is to assess the coverage of disaster issues and disaster risk reduction activities on Ethiopian Media. To study this research, the qualitative data collection and analysis method which are very fundamental to look at the real situation on the ground and deeper insight was used. Specifically, contents of 'Addis Zemen', 'Fortune', and 'Reporter', which are purposely included in the subject of the study, were interpreted. The result shows the Ethiopian print media were not focusing on disaster, and related issues as well as DRR as it is needed. Specifically, the print media in the country have seemingly forgotten to set a purposeful agenda to disseminate salient information regarding disaster to the target audiences.
\end{abstract}

Keywords: Disaster, drought, newspaper, Ethiopia, content 


\section{Introduction}

As many events have been happened in the world, the issues of disasters are appealing issues to the journalists and the audiences. It is because of its sensitiveness of the issues, the magnitude of the impact and the consequence on the human being and directly touches the human life. Ethiopia, as one of the disaster risk areas, it is important to look at how the media cover these issues where there is no empirical research so far. This paper tries to explore and analyze the quality of the Ethiopian Media's Coverage of disaster events/stories and disaster risk reduction. Moreover, the research attempts to assess the capacities and experiences that the media practitioners in giving coverage to disaster issues. To what extent journalists gives attention and focus on disaster issues and how they set agenda on it is also the center of the discussion. The report encompasses, types of disaster got coverage, placement, brief summary of content, quality of coverage, theme and purpose of the items, tone and origin of disaster issues by taking the print media.

The Media in Ethiopia is likely an underutilized force in covering disasters risk reduction and related issues. The role of media as agenda setters, to initiate people to do some disaster risk reduction actions, they seem to have been minimal in Ethiopia. Moreover, even though the efforts done by the government and the others concerned bodies are superb, little attention has been devoted by the journalists.

Hence, the finding of the study will enable Ethiopian Media to consider their coverage on disaster and related issues which have devastating effect in the country's socio-economy, politics, and the life of the large societies. This exploratory assessment on the selected newspapers would help concerned individuals, stakeholders and organizations to initiate media projects to inform and educate the society and to take appropriate actions on Disaster Risk Reduction (DRR) strategies. The findings would hopefully be important in pointing out officials and other pertinent bodies of the media institutes to show how to focus on disaster issues and types of media outlets to be used in DRR campaigns.

\section{A Brief Note on Disasters and the Media}

\section{What are Disaster and DRR?}

Disaster can be defined differently according to the philosophical perception of the scholars' and their disciplines. It can be defined and classed broadly as geography, anthropology, 
sociology, development studies, health sciences and the geophysical sciences with engineering, Perry and Quarantelli (2005). Some others defined it from the religious perspectives. That means they are considering disaster as a punishment, a wake-up call or a betrayal of trust in safety systems, Horlick-Jones (1995) and (Olson 2000) cited in Perry and Quarantelli (2005). There is an increasing tendency to equate disaster with notions of recrimination, scapegoats, negligence and culpability, ideas that have strong moral overtones.

International Federation of Red Cross and Red Crescent Societies (IFRCRCS) in 2002 defined disaster as a situation or event which overwhelms local capacity, necessitating a request to national or international level for external assistance.

According to Garrison (1992), any mass destructions, huge accidents and natural incidences can be regarded as disaster. Disasters can strike suddenly and unexpectedly, anywhere and at any time. The causes may be sudden and unpredictable and the result uncertain and unanticipated. Disaster is a sudden event that brings a great loss and distraction as well as devastation to the life and property of the people indiscriminately. The degree of vulnerability and the damage on the mental, socio-economic, political and cultural states caused by disaster is usually immeasurable and varies with the country's geographical location, climate, landscape and the technological advancement.

The draft National Policy and Strategy on Disaster Risk Management (2010) document defined disaster as the occurrence of an abnormal event triggered by a hazard(s) that impacts a given entity (including a vulnerable community, geographical area, infrastructure or a group of people in significant numbers gathered in one place) causing damage and/or casualties, leaving the affected entity unable to function normally, eroding survival mechanism and forcing it to seek outside assistance for survival.

Disaster can causes wide range of hazards which affect the political, economical, social and cultural values of the countries. By referring the research done by (IFRCRCS 2002), Perry and Quarantelli (2005) pointed out that on average about 220 natural catastrophes, 70 technological disasters and three new armed conflicts occur each year. A more recent finding released form United Nation about disaster statistics revealed that disaster caused by vulnerability to natural hazards killed more than a quarter of a million people in 2010, one of the deadliest years in more than a generation. 
In Ethiopia, one of the poorest countries with poor technological advancement, disaster has been widespread and a common phenomenon. Drought, flood, minor earthquake, volcano, ash and famine are prevalent in many parts of the country. However, the major disaster which is extensively and frequently seen in Ethiopia is drought. It is almost common to here that the country has normally been referred as drought prone area and example of famine. Hunger has been one of the leading problems in Ethiopia for centuries. Even though the magnitude of the effect of drought is quite immense in the low land areas of the country because of the absence of diversified livelihood, drought is among the major hazards affecting livelihoods and welfare of millions of people in Ethiopia. This means that the recurrence of severe drought and other major hazards in the low lands of Ethiopia is a major cause of human suffering and poor livestock production, particularly in pastoral and agro-pastoral systems.

Since disaster can affect everyone and therefore it should be everybody's business and commitment to reduce or control it. Disaster Risk Reduction (DRR) should be part of everyday decision-making: from how people educate their children to how they plan their cities. Each decision can make us either more vulnerable or more resilient. According the guideline prepared for the journalists by the UN, DRR includes all policies, strategies and measures that can make people, village, cities, and countries more resilient to hazards and reduce risk and vulnerability to disaster. This can be included according to prevention, mitigation, preparedness, recovery and reconstruction.

\section{Media and Disaster}

In dealing with disaster, the news media are close behind in reporting the events. Many media agencies have a part in dealing with disaster and its aftermath. The emergency services, hospitals and central government and others may all be involved during the disaster but, the media are always major players both in informing the societies and the government both in the incidence and the action taken by the concerned bodies. They can be an invaluable ally in the provision of information to the public (George, 1999:6).

Disasters contain the very essence of hard news and usually it is breaking news for all news media. Disaster can be listed out from the major car crash to earthquake and the impact sometime is different according to the existing situation, the horrible events and the victim's 
conditions. Based on the magnitude and the impact of the disaster, media give coverage for the incidences. A few stories have powerful to draw the attention of the potential readers.

It is widely agreed that media is the best tool in mobilizing the mass when governments want active involvement of the people in development activities. The mass media plays significant role to seep up social transformation required for development. It has the potential of creating common understanding by raising important ideas, developing, and expanding innovative.

Cognizant to this fact, the Ethiopian government has made an effort in relatively expanding both private and public media. These media are entertaining various development issues. Among the areas where journalists show their maximum efforts is disaster reporting.

Here, it is wise to point out the role that the media play in changing the life style and creating the awareness of the pastoral and agro pastoral communities for the betterment of their livelihoods. To minimize the impacts of drought and creating awareness of policy makers, communities and practitioners on drought/disaster risk reduction, using media seem inevitable. Covering disaster issues in the media effectively is an essential element of managing the incidence and building resilient communities. However, it is observed that there is a tendency among journalists and media houses to give less emphasis to disaster risk reduction and related issues. But journalists/medias seem to give attention to disaster events when they occur. That means by ignoring the correlation functions which is more focusing on media's role in interpreting and analyzing issues scrupulously, the Ethiopian media are relying on doing surveillance task. They are likely paying attention to report disaster events, when the incidences happen and impacted life and livelihoods.

It is the major role of the media to inform the public and other stakeholders. Media is covering about the victims, the public and wider community. Covering the works or disaster relief workers, reinforcing morale, and developing public understanding of their difficulties, public confidence in the handling of the aftermath, are also the role of the media (George, 1999). 
In disaster reporting, it needs to make clear how lines of communication will work, who is to speak on what issue and what can they say? How will they get their message across and to whom? How will information flow be managed into within and out of the organization?

In covering disaster, there is no magic formula to the media handling the incidences. However, regardless of the magnitude, the journalists are expected to cover disaster stories by focusing on basic information. They can focus on the extent of the causality, how it occurs, assess the damage, locate the victim and the witnesses, focus on rescue and other medical cares, determine the public reaction, and other for the point of reporting.

The job of journalists in the news media is to report issues on events. Newspaper editors may differ in their judgments as to which story is the most important. Different publications take differing lines according to their political affiliations, proprietor's interest, or readers concerns on the whole; however, the various elements of the media report the news as accurately as they are able within the constraints under which they work.

Reporters are supposed to be impartial. They are not supposed to get personally involved in events and certainly not to alter the course of events by any involvement they may inadvertently have. They are not supposed to take sides, although the companies they work for might have become increasingly difficult to respect the code of conduct. Telling the truth about a disaster may require a degree of courage on the part of the organization. It is definitely better to have told the truth that to have been found out hiding something questionable. Managers need to have fear of the media, even at a time of disaster, as long as they act with integrity (George, 1999).

\section{Study Design}

With the purpose of exploring the coverage of disaster issues in Ethiopian media, the researcher used qualitative method of study. It is because qualitative method examines the constitution of meaning in everyday phenomena, Lindlof (1991). Qualitative research uses a naturalistic approach that seeks to understand phenomenon in a given specific settings. It will also help to collect data through interview, discussion, observation, and to analyze and interpret them in-depth. Maxwell (2005: 22-23) also stated that one of the goals of qualitative research is to understand the meaning which relates to the research's endeavors to perceive 
the events, situations and experiences people are involved in. In other words, as observed by Byman (1988: 61), qualitative research has an expressed commitment to viewing events, actions, norms, values etc from the perspective of the people who are being studied. Hence, due to the main objective of the research and the time frame, only qualitative data collection and analysis method was used.

\section{Population of the Study}

In order to complete and to come up with a comprehensive out of the research, the paper tried to use large population. As a result of that a period from 2001 to 2010 which was purposively selected to get large data and to maximize the chance of getting data (from the researcher's media experiences, media houses are not commonly and frequently covering disaster issues) was taken as the sampling frame for the study. Moreover, it would allow the researcher to come-up-with a wide-ranging of finding and forward well-established recommendations.

\section{Subject of the Study and Sampling Size}

In order to meet the purpose of the study, intentionally selected subjects from the population mentioned above were taken. Here, it is wise to mention that the subject of the study (from Ethiopian Media- there are about 20 newspapers, the researchers had taken three newspapers, namely Addis Zemene from the public, Fortune and Reporter from the private owned, by considering their reputability, large readerships and credibility (Ward 2011).

By the nature of the qualitative research which would take small number of sample and depth analysis, the research had taken about 21 stories of the newspapers from these newspapers and discussed qualitatively and presented thematically.

\section{Findings and Interpretation}

\section{Types of Disaster}

According to, Garrison (1992) any natural incidents and intensive mass destruction is considered as disaster. Based on this definition, disasters are many in types. In the purposively selected Ethiopian media, a considerable number of stories on drought and famine, which can be controlled by good policy interventions and preparedness, got coverage. A few numbers of floods, volcanoes, and plane crash stories were also observed in 
the private and government newspapers. Flood in Diredawa and South Omo Zone, global warming, forest fire in Arisi, landslide in Arbaminch and others were also get coverage. It shall be recalled here that disaster by itself and its impact are wide so the media shall meticulously focus on all when possible.

\section{Placement and Coverage of Disaster Stories}

Journalists' prioritization and concern given to one issue would be determined on the placement of that content. The place where the story is posted on the newspapers and the time it is aired indicate that the journalists or the respective media houses give due attention and priority on those particular issues. During the sample period, almost all the articles and news were placed in the inside pages of the newspapers. Only one news item was found in the first page of 'Addis Zemen' Newspaper. This news item was covered on the first page of the newspaper because it was all about a call of the government for donation of food and other required facilities for 4.5 million drought affected people in the country. Surprisingly, no item was found in the first page of 'Fortune' and 'Reporter' newspapers. Most stories were covered in the inside and backside page of the newspapers which means that either the issues were considered poor or the media practitioners gave a little attention to disasters issues. This shows that disaster issues have been given scant attention on the Ethiopian print media.

As it is mentioned above, professionally, if issues have posted on the first page of the newspaper, it is called that media institutes prioritized and make that issues an agenda of both the government and the society, (MaComb and Shaw 1977).

Even though editorials and opinion pages on the newspapers are very important and significant to bring attitudinal changes and impact on the readers, the research did not read even one article. This means that either writers or media owners seemed to have forgotten disaster issues. From this, it is possible to say, the Ethiopian print media are not setting agenda and prioritizing disaster issues at large.

\section{Brief Summary of the Content of Disasters}

The issues which were treated on the newspapers are mainly and largely talking about drought and famine. The newspapers, especially the private owned newspapers, thoroughly discussed on the recurrent and criticality/severity of drought and famine in the country. Those 
articles aggressively discussed the failure of the Ethiopian government to take appropriate measures to control the recurring drought. Moreover, the article dealt about the extreme effects of drought and famine on children, women and their life.

To indicate here, all critically discussed ideas on the newspaper were either written by anonymous contributors or UN agency staff members. Here, it is fair to conclude that the journalists are likely either not courageous to write critical comments and reviews on the serious problems of drought and famine or not have enough understanding about those issues.

Whereas, calls from Ethiopian Meteorology Agency about delay of rainfall in Belge (March April rain) and related harvest problems to aware the concerned bodies to take timely measures have taken the largest shares of the government print media; an issue on the government owned newspaper covered government's preparation to control forest fire in the Gambela region.

It is crucialhere to recall that a known media scholar, Griffin (2006) underlined that the press may not be successful much of the time in telling people what to think but it is stunningly successful in telling its readers what to think about. In this regard, the Ethiopian media is not largely working to set disaster issue as agenda that the people discuss on it. The media is almost not playing a role to mitigate the effects of disasters by covering early warning issues to take preemptive action to minimize the risks and the dangers. As the media role, informing and educating, the print media are almost never seen in letting the societies and the other concerned bodies to know and take appropriate actions to the problems. Form the contents written on the newspapers, it is possible to say journalists seem not passionate, committed and ready to cover disaster issues as the profession expects from them. They are less courageous on these devastating issues to critically discuss stakeholders' weakness like governments and other national and international actors and in bringing long lasting solutions to this drought prone country.

\section{Sources of Disaster Stories}

The starting point of the stories helps to know the main and common sources of the articles and news. It helps to identify to what degree prime victims such as farmers, pastoralists, agro pastoralists and others at grassroots level communities being used as sources by the 
journalists. Where to fetch the data help to get the right/ relevant information and take appropriate action on time according to the circumstances on the ground.

It is found that the newspapers used only government officials, NGOs and foreign experts as the sources of the articles/news items. The grassroots and the prime victims of the disasters were forgotten in many of the stories and programs. It can be concluded that journalists are not able to go to the fields on the exact place of the problem happenings. Observing the existing circumstances on the ground or the grassroots peoples/victims ideas were ignored and their voice were entirely denied. Here, from the perspective of development of communication, the grassroots have the right to address expression of their needs, considering their participations by putting the emphasis on the needs and their view points of the individual and groups are very decisive (Yoon 2004).

\section{Writing styles, clarity and simplicity of the articles}

Regarding professionalism, it is better to take clarity and simplicity of ideas, appropriate use of numbers, balance and fair, using picture and other inputs, and attractiveness into consideration. During the sample period, both the strong and weak side of reporting disaster issues was monitored on the media.

The strength was that some of the articles and news stories were written reasonably well by using various inputs which enhance the clarity and draw the attention of the readers. Some of the stories were supported by pictures, charts and written in a simple and clear language. Current and timely issues were also discussed and written attractively. In this regard, it is possible to say that most of the items were written professionally. Even anonymously written articles and feature were critical and fair.

However, identifying the weak side of the disaster covering, numbers were not properly written in some of the news stories on the newspapers. As mentioned earlier, the common problems of the newspapers is journalists are mainly depend on government and official sources by ignoring or forgetting the victims and the grassroots people. In brief, the feelings, the situation and the exact features of the problem were not discussed from the primary sources. 
Moreover, the other professional problem observed in the newspaper is the data and the critical facts are not citied. Long transcribed interviews were read on the newspapers. Besides, redundancies, lack of consistency on the issue and, flow of narrations were observed.

One-sided information is also another problem. For example, the private newspaper are using foreign officials and donors as sources of information whereas the public media are using government officials and favoring ruling party's performance.

It is observed that items written during the sample period were owned and managed by the direct involvement of government as a source of information, operation, and owning the content. It means that the other concerned bodies, NGOs, International organizations' engagements and involvements seem quite minimal. It is better to stress that without full engagement of all stakeholders, Disaster Risk Reduction is not possible.

To sum up, even though there are some journalists exerting certain efforts to produce appropriate DRR issues, it is possible to say they lack professional and ethical capacity to produce print materials due to lack of training and education.

\section{Theme and Purpose of the Items}

According to MacLiesh (2006), theme of the items refers to the central message or the dominant theme of the stories. With the wide-commonly purpose of the media, informing and educating the people, most of the items especially those which were dealing with call-toaction were observed focusing on the theme of mobilizing the large societies and motivating people for further actions. It is possible to put clearly that some of the articles were observed with the theme of raising awareness of the people about disasters. It is worth mentioning that articles and news items shown weaknesses to point out the government and people to prepare and take anticipatory actions. Similarly, it was observed that policy and strategy issues, interventions and early warning and disaster risk reduction issues were not the prime purpose of the media. Surprisingly, many of the articles were reported for the sake of reporting without ultimate output just to please certain government bodies. However, Fissha (2007) and, Ali (2000) highlighted that mass media have been seen as a mobilizing agent for national building by diffusing new technologies and innovation, policy interventions and awareness 
creation in the modernization theory. To this effect, the Ethiopian media gave less coverage to the Disaster Risk Management issues with these specific themes.

The basic concerns of the media regarding disaster issues during the sample period were to inform the society for mass mobilizations. Some of the stories were covered to point out problems and directions and some were covered for the sake of reporting.

\section{Tone of the Items}

Regarding the tone of the articles in print is usually related with ownership. Almost all the public media items which were reviewed had the tone of positive or appreciating the government initiatives and ideas. That means they are not discussing ideas and activities critically and forwarding comments which could help as inputs to solve the problems. Even though informants from the government media noted that they are trying to write the stories in pointing out problems with justified facts objectively, the media outlets showed that they are covering only positive actions and successful performances of the government without balancing the strong and weak side of the interventions. However, this is not the guaranty for the government to secure and implement its projects in disaster prevention. Napoli (1996) clearly articulated that if the journalists cover only positive achievements of the government, it would not be a guaranty to bring sustainable changes in any country. Hence, if the media only focus on success stories, even it will be difficult to implement the current DRM policy of the country which is under ratification. Media shall be fair, balance and neutral as well as critical in both appreciating the strong side and commenting on the weak side of the government's performance on disaster issues which enable the management, the societies, and other stakeholders to control the problem and bring sustainable solution.

\section{Origin of the Issues}

As the role of the media in DRR strategies is to serve as an agenda setter, journalists shall cover disasters issues by planning, investigating and exhaustively examining the cases. This would mean that 'where the information is gathered' is one of the determinants of the media agenda setting roles.

Regardless of this fact, most of the reviewed articles were covered from reports, events and documents. This means that the journalists are seemingly less agenda setter on disaster issues. 
Of course, there were stories covered by using interviews but they were insignificant in number and might be covered by direct or indirect drive of the government and other actors. It is possible to say that Ethiopian print media are not playing agenda setting roles on disaster stories to control and minimize its risks.

Moreover, the newspapers which were scanned were written by junior journalists and contributors. Specifically, on the private media, all those critical issues were written by contributors. Items produced on the government owned media were entirely written by their journalists.

\section{Conclusion}

As the universal role of media is to disseminate educational, informative and entertaining issues to the public, so as to help the stakeholders in the process of bringing changes in people's attitudes and experience, the Ethiopian print media is less likely to focus on disaster related issues, particularly DRR which may serve the country as the way out from catastrophic situations. Besides, the selected print media in the country have seemingly forgotten to set a purposeful agenda to disseminate salient information regarding disaster to the target audiences. Based on the importance of agenda setting for the journalists to influence the societies by raising important issues, the journalists of the selected media are not in a position to set agenda and bring societal awareness on disaster risk management issue which has crucial countrywide impacts. As media practitioners, journalists have the responsibility of setting particular issues on the public agenda; however, this was found as a failure in Ethiopian Media and its respective journalists.

Even though farmers, pastoralist and agro-pastoralists and other poor grass-root communities who were the prime victims of the effect of disasters, they were not used as sources in most of the stories. On contrary, higher government officials were the dominant sources of the stories and hence, the flow of information was found to be top to down. The recommendations would not go with the existing situation of ignoring the grassroots source.

The majority of the items analyzed were covered in a positive tone, which could have been better covered by incorporating all sided stories. If they covered critically from different angles in order to give a wide range of information about the activities of the government, it would have enabled concerned bodies to point out root causes of disasters and look for 
sustainable solutions. Unfortunately, the public media lacks balance- covering the positive sides of stories that never bring sustainable solution.

The government owned Ethiopian media have been covering the issues in such a way that it pleases the heads. Whereas, the private once are by far tried to be neutral and fair. 


\section{References}

Ali A. (2000). Coverage of Economic Development reporting from the Development Journalism Perspectives, Ethiopian Press enterprise Journals volume 1, number 1. Berger G. (1998), media and Democracy in South Africa, Review of African Political Economy, Department of Journalism and media Studies, Rhodes University, South Africa, POAPE Publication LTD

Byman, A. (1988). Quality and Quantity of in Social Research, London: Unwin Hyman.

Dominick J.R., and Wimmer R.D. (2006). Mass Media Research, An Introduction, $8^{\text {th }}$ edition, Thomson Wadsworth, USA.

Fissha H. (2007). Content analysis of development news stories in Addis Zemen 'Newspaper, unpublished paper, AAU, Addis Ababa,

Garrison B. (1992), Advanced Reporting Skills for the Professional, University of Miemi, Lawerance Erlbaum Associations, Published Hillsides, New Jersey.

Griffin E. (2006). Communication, A first out look at communication theory, $6^{\text {th }}$ edition, McGraw-Hill Higher Education, America, New York.

Lindlof, T. (1991). Qualitative Communication Research Method, London Sage Publication Maxwell, J. (2005), Qualitative Research Design: An Interactive Approcah. $2^{\text {nd }}$ Edition, Applied Social Research Methods Series, Volume 41. London: Sage Publication.

McCombs M. and Shaw D. (1977). The Emergence of American Political Issues. New York. West Publishing Co, 1977. (http://www.jstor.org/view/0033362x/dm991702/99p0440q/0

McLeish R. (2005), Radio Production, fifth edition, published on Focal Press. Netherlands. Melkote S.R. and Steeves H.L. (2001). Communication for Development in the Third World, Theory and Practice for Empowerment, $2^{\text {nd }}$ Edition, Sage publication, New Delhi.

Miller K. (2005). Communication Theories: Perspectives, Processes, and Contexts, $2^{\text {nd }}$ edition. New York: the McGrand-Hill

Napoli J.J. (1996). Media, National Development and the Middle East, Volume 46 page 177-184, December 1996, America University of Cairo

Natasha, M and et la. (2005), Qualitative Research Methods; A Data Collector's Field Guide. North California; Family Health International, USAID

Perry W.R and Quarantelli E.L. (2005), What is A Disaster? New Answer to Old Questions, International Research Committee on Disasters, United States. 
Servaes J. (1999). Communication for Development, one world, multiple cultures, Katholieke University Brussel, Hampton Press, INC.

UNISDR (NoYe), Disaster Through A Different Lens, Behind Every Effect, there is a cause, A guideline for Journalists covering Disaster risk reduction, Untied nation , (2010) National Policy and Strategy on Disaster Risk Management , A draft Document, Federal Democratic Republic of Ethiopia

Ward, D., (2011), Audience Survey Ethiopia 2011, Electoral Reform International Service, ERIS 